\title{
A Model for Improved Knowledge Management Performance in Higher Education Institutions in Developing Countries: A Case of Zambia
}

\author{
Walinase Kaira ${ }^{1}$, Jackson Phiri ${ }^{2}$ \\ ${ }^{1}$ Graduate School of Business, University of Zambia, Lusaka, Zambia \\ ${ }^{2}$ Department of Computer Sciences, School of Natural Sciences, University of Zambia, Lusaka, Zambia \\ Email:wanak22@gmail.com, Jackson.phiri@cs.unza.zm
}

How to cite this paper: Kaira, W., \& Phiri, J. (2022). A Model for Improved Knowledge Management Performance in Higher Education Institutions in Developing Countries: A Case of Zambia. Open Journal of Business and Management, 10, 543-563. https://doi.org/10.4236/ojbm.2022.101030

Received: November 1, 2021

Accepted: January 27, 2022

Published: January 30, 2022

Copyright $\odot 2022$ by author(s) and Scientific Research Publishing Inc. This work is licensed under the Creative Commons Attribution International License (CC BY 4.0).

http://creativecommons.org/licenses/by/4.0/

\begin{abstract}
Knowledge management is an organizational process of creating a centralized knowledge source that enables acquiring, assimilating, distributing, integrating, sharing, retrieving and reuse of internal and external, explicit and tacit knowledge to promote innovation in the organization. Higher education institutions are not an exception and must be at the center of knowledge management practices as they are the major producers of a country's workforce. The knowledge from individuals, systems and collaborations with other institutions can only be properly appreciated by way of having a well-executed knowledge management system in place. Whilst knowledge management is seen to be a very important practice to have in a higher education institution, in Zambia, knowledge management systems do not seem to be given the deserved importance and consideration by higher education institutions. The primary aim of this study is to propose a model that would assist with the knowledge management implementation process in higher education institutions in Zambia. Four higher education institutions were purposively selected to give an overview of the status of KM practice, namely: the University of Zambia, Mulungushi University, Chalimbana University and the National Institute of Public Administration (NIPA). This study adopted a mixed method approach, that is, qualitative and quantitative research design for analyzing research questions and for effective interpretation of data from the questionnaire. Both online and hardcopy questionnaires were distributed among the respondents. IBM Statistical Package for Social Sciences (IBM SPSS) version 20 was used to analyze the data. For data analysis, descriptive statistics and inferential statistical tests (Pearson Chi-square) were used. The results revealed that the majority of the respondents have a good level of knowledge management awareness; however, it is not commonly practiced in
\end{abstract}


the institutions. These institutions do not have knowledge management policies or strategies in place and there is no presence of a KM department. If there is one, probably on paper but not established nor practiced. The study proposed a model that would guide the adoption process of knowledge management practices in higher education institutions in Zambia, by highlighting some critical success factors from the four categories of CSF as proposed by the Heisig (2009) model.

\section{Keywords}

Knowledge, Knowledge Management, HEI, Model, Knowledge Management Cycle

\section{Introduction}

In today's society, knowledge has become such a key component of running day-to-day affairs. Knowledge, currently and in the future, symbolizes a power source that supports progress and competitive advantage because it reflects the most important source for the organizations, societies and the individuals (AL-Hayaly \& Alnajjar, 2016). In the past, it was common for organizations to manage tangible goods more than knowledge assets (Lyu et al., 2016). Many organizations have undergone major shifts from tangible goods to investing more in knowledge as an asset. Kumaravel and Vikkraman (2018), state that because knowledge facilitates competitiveness, economies have adopted it as the most key asset for growth. A knowledge-based economy is expected to promote an environment for innovation by reinforcing the delivery of better quality education and fostering innovation and technology (Pook et al. as cited in Kumaravel \& Vikkraman, 2018).

Academic institutions, particularly higher education institutions such as universities and colleges are seen as "knowledge hubs", where diverse activities are carried out for the generation, preservation, diffusion and application of knowledge (Hoq \& Akter, 2012). Hoq and Akter emphasize that university knowledge management systems must take adequate measures to foster creation and sharing of knowledge among the researchers as well as the teaching and non-teaching staff, students, patrons and other stakeholders. Bhusry et al. further explain that an academic institution is made up of different units that consume as well as create knowledge, they consist of faculty, students, administration, academics, research, training and placement. For this reason, it is important to be aware of the knowledge that each unit contributes to the system and the knowledge that each unit requires to perform its functions, and find ways to apply this knowledge effectively at the points of use, in order to meet the institute's goals and targets.

In light of the above, the main purpose of this research was to develop a $\mathrm{KM}$ 
model that will help to improve KM in the Zambian HEIs. This paper also gives insights into the present state with regards to KM in HEIs in Zambia. This paper is limited on low response rate from the respondents; data was analyzed using both descriptive statistics and inferential statistics. However, for inferential statistics only the chi-square tests were performed on the identified variables. The paper is organized as follows: Section 2 is the Literature Review, Section 3 highlights the theoretical background, Section 4 shows the Research Methodology, Section 5 outlines the Study results and discussions and, Lastly, Section 6 focuses on the conclusions and recommendations of the study.

\section{Literature Review}

\subsection{Defining Terms}

\subsubsection{Knowledge}

Knowledge is the insights, understandings, and practical know-how that people possess (Omotayo, 2015). Kakabadse et al. as cited in Ho, 2018 states that knowledge is not a visible or physical asset, and is acquired through a complex intellectual process of perception, learning, communication, association and reasoning, and that it is classified into two: tacit and explicit knowledge. Tacit knowledge is defined as knowledge embedded within the head/minds of people whereas explicit knowledge is recorded and well documented information that helps in taking action and also expressed in formal language. It is knowledge that is published, always available for use and can be articulated, captured, presented and codified (Dhamdhere, 2015). It is rooted firmly in action, procedures and processes, commitments and values and can only be indirectly accessed.

\subsubsection{Knowledge Management}

Knowledge management is applied in many different disciplines and therefore does not have a standardized definition. Each given definition has a particular emphasis depending on the area of discipline. And in most cases, giving too many definitions awakens unnecessary debates. Knowledge management is an organizational process of creating a centralized knowledge source that enables acquiring, assimilating, distributing, integrating, sharing, retrieving and reuse of internal and external, explicit and tacit knowledge to promote innovation in the organization (Siregar et al., 2019). Torabi and El-Den (2017) define knowledge management as the process of capturing, developing, sharing, retention, and effectively using organizational knowledge.

\subsubsection{Higher Education Institution (HEI)}

Higher education comprises all post-secondary education, training and research guidance at education institutions such as universities that are authorized as institutions of higher education by state authorities.

\subsubsection{Model}

A model is an informative representation of an object, person or system. A KM 
model is a structured way to look at the process of KM used by an organization in order to investigate its properties and tailoring it to the organization's specific needs (Paul, n.d).

\subsubsection{Higher Education Institution (HEI)}

Knowledge management cycle (KMC) is a process of transforming information into knowledge within an organization, and it outlines how the knowledge is captured, processed, and distributed in an organization (Mohajan, 2016). In this continuous process, information is identified, obtained, refined, shared, used, stored and dissociated.

\subsection{The Importance of Knowledge Management in Higher Education Institutions}

Academic institutions are made up of different units that consume as well as create knowledge, they consist of faculty, students, administration, academics, research, training and placement. For this reason, it is important to identify the knowledge that each unit contributes to the system and the knowledge that each unit requires to perform its functions, and find ways to apply this knowledge effectively at the points of use, in order to meet the institute's goals and targets. $\mathrm{KM}$ assists to capture new customers and markets while at the same time retaining existing ones, and this can only be done successfully if there is an established structure to help understand and identify the critical knowledge needed to execute the organization's strategy (Cabrita, Machado, \& Grilo, 2010). KM can improve decision-making capabilities, reduce product development cycle time, improve and reduce costs of academic and administrative services (Maponya as cited in Ngoc-tan \& Gregar, 2018). According to AL-Hayaly and Alnajjar (2016) $\mathrm{KM}$ practice is important in higher learning institutions as it; contributes to the innovation and creation initiatives by the teaching staff members in the universities; contributes to enhancing the psychological empowerment of the teaching staff members in the universities; Increases the university capability to contribute to the economic development and making it more effective in playing the fruitful economic role through serving the stakeholders and the business owners, and developing the human capital. KM is also seen to be a very important tool when it comes to systematic management in libraries (Balague, Duren, \& Saarti, 2016). Islam et al. as cited in Balague et al., 2016 state that KM has the potential to help libraries become more effective through exploitation of users' knowledge and ideas and also by eliminating redundant procedures.

\subsection{Knowledge Management in Zambian HEIs}

Literature reviewed indicates that higher education institutions in Zambia seem to be in the dark and not well informed when it comes to knowledge management. A research conducted by Kabilwa and Maasdorp (2017) on two highest learning institutions in Zambia, namely the University of Zambia and the Cop- 
perbelt University indicates that higher education institutions in Zambia are in an unconcerned knowledge management state. Another study done by Wamundila and Ngulube (2011) concluded that the University of Zambia's challenges regarding loss of knowledge posed threats on its capacity to perform operations efficiently and effectively. This knowledge loss was greatly due to staff attrition challenges such as retirements and resignations. The study revealed that very few work processes and tasks were documented. Workforce planning was not practiced and skills and competency inventories were lacking (Wamundila et al.). Chitumbo and Kanyengo in their 2017 study titled "Knowledge Management Culture among Library Cataloguers: the University of Zambia Library Experience" shows that there is little knowledge sharing and transfer among cataloguers, especially in terms of creation, capturing and refining of knowledge by cataloguers.

In the Zambian higher education institutions, knowledge management has not yet been given proper consideration as a means for institutional growth and expansion, through building knowledge for problem solving and decision making. Literature reviewed indicates that higher education institutions in Zambia seem to be in the dark and not well informed when it comes to knowledge management. A research conducted by Kabilwa and Maasdorp (2017) on two highest learning institutions in Zambia, namely the University of Zambia and the Copperbelt University indicates that higher education institutions in Zambia are in an unconcerned knowledge management state. Another study done by Wamundila and Ngulube (2011) discovered that the University of Zambia's challenges regarding loss of knowledge posed threats on its capacity to perform operations efficiently and effectively. This knowledge loss was greatly due to staff attrition challenges such as retirements and resignations.

In a research paper discussing research practices of academics in African University setting, Twaambo (2018) indicates that, the University of Zambia has not fully utilized its knowledge management strategies to create a favorable research environment in spite of funding difficulties. Mvula (2018), further declares that UNZA may have some knowledge management enablers and practices to some extent, however, did not introduce knowledge management formally and deliberatively. There is very little literature about knowledge management related studies in Zambian higher education institutions. This review partially, confirms how uninformed Zambian institutions of higher learning are in terms of knowledge management strategies.

There is very limited research conducted on knowledge management in HEIs in Zambia. Very little is known about the status of KM in the HEIs and how it is implemented, if at all it is. The limited literature reveals that HEIs in Zambia are not that concerned about knowledge management and its implementation. This study will add on to the gap in literature on the state of knowledge management in HEIs in Zambia. The study does not just include UNZA, but an overview from the point of view of other HEIs namely; Chalimbana University, Mulun- 
gushi University and NIPA. No study was found about knowledge management in other higher education institutions in Zambia apart from those highlighted in the above literature review, and these are the University of Zambia and one on the Copperbelt University in Zambia. Wamundila and Ngulube (2011) stated that the University of Zambia has been undergoing loss of knowledge due to staff attrition challenges such as retirements and resignations. If UNZA had a proper knowledge management system in place, the knowledge loss would not have been experienced because the implemented system would have ensured that people's tacit knowledge is extracted and stored in a database or passed on to others. The fact that UNZA could have some knowledge management enablers and practices to some extent according to Mvula (2018), is not good enough. $\mathrm{KM}$ enablers need to be defined and put in the KM system in these HEIs when reviewing institutional knowledge management system. This study proposed a knowledge management model with properly defined knowledge management enablers that must be put into proper consideration as HEIs prepare for a $\mathrm{KM}$ system or even during a performance review or a KM system.

Another study by Chitumbo and Kanyengo (2017), concentrated on studying Knowledge Management Culture among Library Cataloguers, which tackled just one specific section in the institution and did not give a general overview of the KM culture in the entire institution. In this study, the researcher gave a general overview of the knowledge management culture at an institutional level. Kabilwa and Maasdorp (2017) conducted a study to determine the state of Knowledge Management in Higher Education Institutions in Zambia, which was just exploratory research and only studied two universities, the University of Zambia and the Copperbelt University. In this study, the researcher did not just highlight the status of knowledge management in 4 HEIs but also went further to propose a KM model.

\section{Theoretical Background}

\subsection{Knowledge Management Cycle}

Mohajan (2016) states that the knowledge management cycle systematically shows how organizations handle knowledge at various stages of their life within the organization and also shows how information is transformed into knowledge via the creation and application process. Evans et al. (2014), identified some of the most influential knowledge management life cycles in chronological order as follows: Wiig (1993), Meyer and Zack (1999), Bukowitz and Williams (1999), McElroy (2003), Dalkir's (2005) integrated life cycle model and Heisig's (2009) framework. However, Dalkir's (2005) and Heisig's (2009) were only reviewed for their contribution. By integrating the previously studied models, Evans et al. advanced a KMC model which consists of seven phases; identify, store, share, use, learn, improve, and create.

Through knowledge management systems, data can be transformed to information, knowledge and to wisdom that could help organizations make better 
decision which will enhance the achievement of their goals (Ho, 2018). Before the processes begin, different reasons may initiate knowledge requests, which may include strategic and/or operational problem solving, decision making, knowledge gap analysis, or innovation. The request for knowledge prompts the searcher to either identify if the requested knowledge exists in house or if it needs to be created or acquired. The seven processes identified in the Evans et al. (2014) KMC model are explained below;

1) Identify: This stage involves extracting codified and encapsulated knowledge assets such as documents in electronic and printed form, stored in a knowledge databank. Tacit knowledge is also identified at this stage through brainstorming sessions, network analysis or workshops.

2) Create: If during the identify stage, the required knowledge is not found while searching, new knowledge assets may need to be created. Examples of common organizational initiatives that may be employed in the creation of new knowledge assets include expert interviewing, prototyping, information and workflow analysis, and competence and process mapping.

3) Store: Once valuable knowledge is acquired and validated, it must be stored as an active component in the organization's repository. Knowledge assets need to be stored in a structured way that allows for proper and efficient manipulation, retrieval, and eventually sharing.

4) Share: Stored knowledge assets are retrieved at appropriated times in order to be shared both internally and externally. Sharing times and frequencies can happen as and when knowledge is needed, or can be practiced through pre-established processes. Tacit forms of knowledge may be shared through coaching, mentoring, and apprenticeships programs as well as through storytelling, narratives, and anecdotes.

5) Use: Knowledge that has been shared must be put to good use in order for the organization to realize its value. The appropriate knowledge may be applied to solve problems, make decisions, improve efficiency, or promote innovative thinking. Common activities that assist in this stage include developing communities of practice, workshops, and tutorials. Some of the technologies engaged in these activities include, incident and help desk systems, expert systems, and communication and collaboration technologies. Additionally, KM can only be considered effective if this stage is successfully accomplished as KM can only succeed if knowledge is used appropriately.

6) Learn: Knowledge that has been shared and used can also serve as the basis for refining existing and creating new knowledge assets. In this phase knowledge blocks are reviewed, it also involves integrating, connecting, combining, and internalizing of knowledge. If knowledge assets are found to be valuable upon following established analysis and assessment criteria, they progress to the improve stage for further refinement and/or codification/encapsulation activities take place. However, for those knowledge assets that have been deemed unsatisfactory the searcher returns to the identify and/or create phase in order for more 
knowledge assets to be identified or created following the discovered gaps, thus triggering the life cycle to begin all over again.

7) Improve: The learn phase helps to further polish the knowledge assets by identifying or creating new value while updates are made in order to keep them current and relevant. The knowledge assets are repackaged to be stored or referenced so that their value may be successfully applied in the future. Common activities used in the improve stage include after action reviews, reflection time, and adapting lessons learned (Figure 1).

\subsection{Critical Success Factors of Knowledge Management Implementation}

According to Moghaddam, Mosakhani and Aalabeiki (2013), there are different understandings of knowledge on the organizational level and that a uniform understanding of the term knowledge does not exist in KM frameworks. There are several definitions of the term knowledge in literature; some are technology driven KM while the majority define KM as a set of activities or processes of developing and exploiting knowledge to achieve or enhance a variety of outcomes such as organizational objectives, value, long-term performance, overall success, or competitive advantage (Heisig, 2009 as cited in Moghaddam et al., 2013). Earlier studies have identified a number of factors that could have an effect on the success of KM implementation. Even though a broad range of factors which influence the success of KM implementation exist, most researchers have agreed on seven widely accepted CSFs. These critical success factors are human resource management, information technology, leadership, organizational learning, organizational strategy, organizational structure and organizational culture. However,

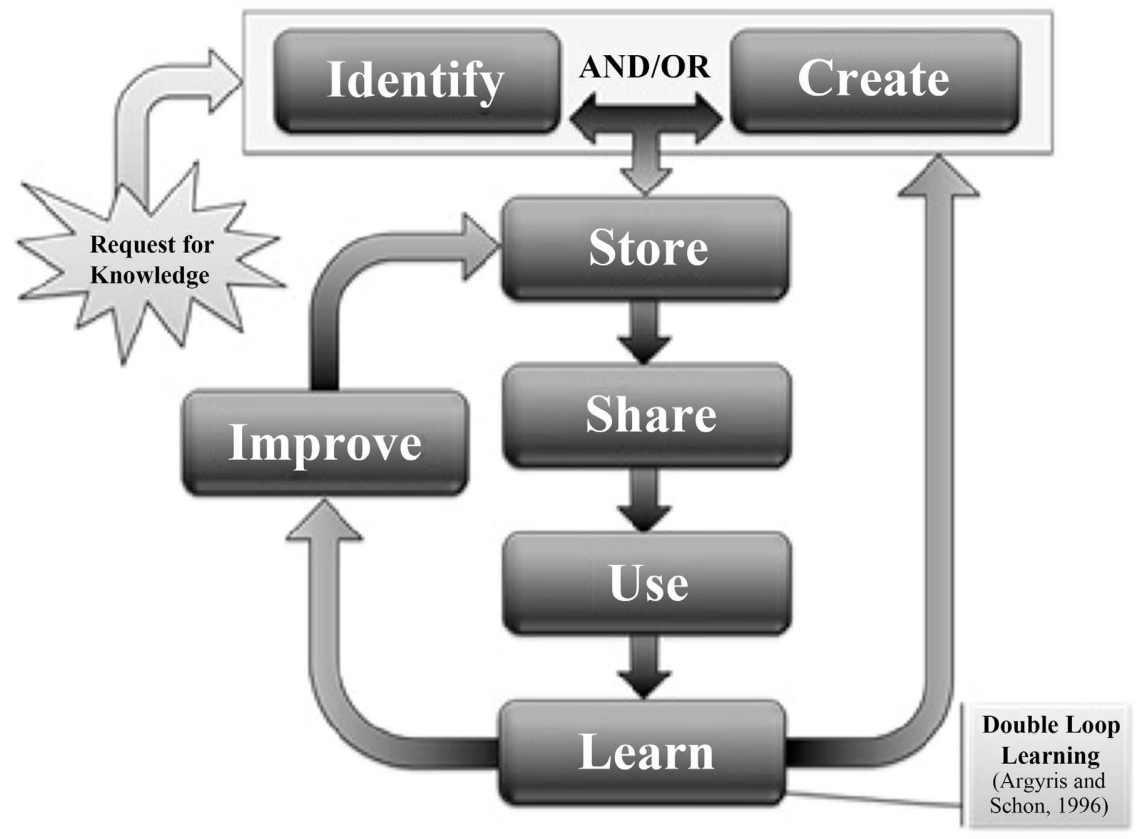

Figure 1. KMC model. Source: Evans et al. (2014). 
Wong as cited in Moghaddam et al., 2013, suggested that no systematic work exists on characterizing a collective set of CSFs for implementing KM in every sector. There are several models which represent dimensions of KM critical success factors, Allameh et al. (2011) identified technology, structure and culture. Further research done by Allameh et al. (2011) identified the following models by other researchers: Laupase (2003) identified organizational structure, culture and information technology, Syed-Lkhsan and Rowland, 2004 identified five enabling factors: organizational culture, organizational structure, technology, human sources and political factors, Ngok (2005) identified: organizational communication system, communal culture, transformational leadership and information technology. Lee and Roth (2009) identified four domains that are pivotal in the study of knowledge management, these are leadership, culture, technology, and measurement. Heisig (as cited in Fteimi, 2015), was able to distinguish between human-oriented factors, organizational factors, technological factors and managerial factors. The proposed model of this paper was guided by the Heisig (2009) model, however without the technology factor. The Heisig (2009) model was adapted from 160 frameworks worldwide, and its four categories were broken down as follows:

1) Human-oriented factors: culture-people-leadership,

2) Organization: process and structure,

3) Technology: infrastructure and applications,

4) Management process: strategy, goals and measurement.

This paper chose one factor from each category but excluded the technology category and the researcher added the policy factor as follows:

- Strategy-An organizational strategy is the sum of the actions a company intends to take to achieve long-term goals. Together, these actions make up a company's strategic plan (Johnson, 2019).

- Culture-Organizational cultures represent the character of any organization, which directs its employees' day-to-day working relationships and guides them on how to behave and how to communicate within the organization, as well as guiding how the company hierarchy is built (Tseng as cited in Moghaddam et al., 2013)

- Structure-Organizational structure is a way or method by which organizational activities are divided, organized and coordinated (Ahmady, Mehrpour, \& Nikooravesh, 2016).

- Policy-is a set of general guidelines that outline the organization's plan for tackling an issue. Policies communicate the connection between the organization's vision and values and its day-to-day operations (Snook, 2021).

\subsection{Research Model and Hypotheses}

Based on the proposed research model, hypotheses of this research are as follows:

H1: There is a significant relationship between organizational strategy and 
knowledge management practice

$\mathrm{H} 2$ : There is a significant relationship between organizational culture and Knowledge management practice

$\mathrm{H} 3$ : There is a significant relationship between organizational structure and knowledge management practice

H4: There is a significant relationship between organizational policy and knowledge management practice (Figure 2).

\section{Research Methodology}

This study followed a descriptive research design and adopted mixed method approach, that is, qualitative and quantitative methods were employed to analyze research questions and for effective interpretation of data from the questionnaire. The research instrument used was a survey questionnaire which was distributed as a hardcopy to the recipients as well as online using google forms. The collected data was entered and analyzed using IBM Statistical Package for Social Sciences (IBM SPSS) version 20 was used to analyze the data. Furthermore, Microsoft Office Excel 2013 was also used to translate some of the data into graphical representations such as pie charts and bar charts. The Cronbach's alpha test was done in order to measure the internal consistency and reliability of the scales used in the questionnaire. The Cronbach's alpha test gave a value of 0.940. Table 1 illustrates the results of the Cronbach's alpha test The Cronbach's alpha is commonly used to measure internal consistency or reliability when there are multiple Likert questions in a survey/questionnaire that form a scale and one would like to determine if the scale is reliable (Laerd Statistics, 2020). The general rule of thumb is that a Cronbach's alpha of 0.70 and above is good, 0.80 and above is better, and 0.90 and above is best (Statistics Solutions, 2021).

This study surveyed four higher education institutions in Zambia, namely; The University of Zambia, Mulungushi University, Chalimbana University and

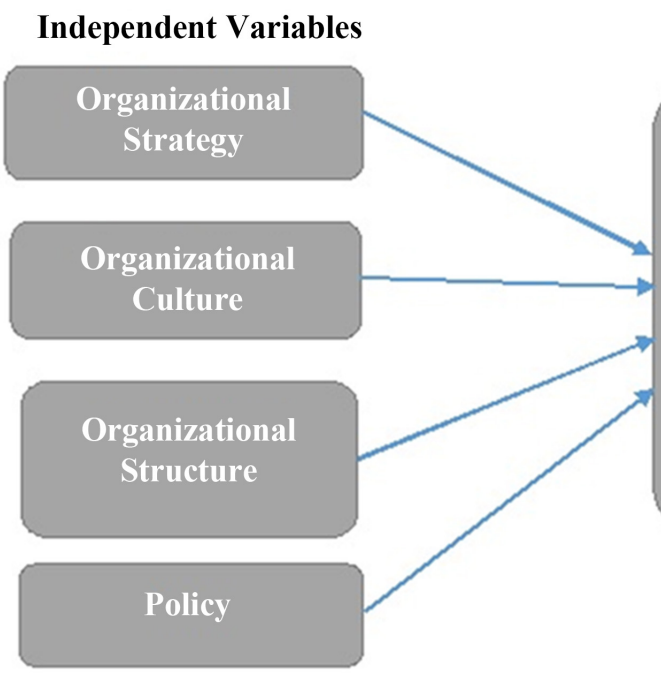

\section{Dependent Variable}

Knowledge Management practice:

- KM Identification

- KM Capture

KM Storage

KM Retrieval

- KM Sharing

KM Use

- KM Improvement

- KM Discarding

Figure 2. Conceptual framework. Source: Researcher's construct. 
Table 1. Cronbach's Alpa reliability test results.

\begin{tabular}{ccc}
\hline Reliability Statistics & & \\
\hline Cronbach's Alpha & $\begin{array}{c}\text { Cronbach's Alpha Based on } \\
\text { Standardized Items }\end{array}$ & N of Items \\
\hline 0.940 & 0.940 & 35 \\
\hline
\end{tabular}

Source: study analysis.

National Institute of Public Administration (NIPA). The participants in this were university staff members at all levels and were treated as one homogeneous sample, without categorizing them into different categories such as academicians, administrative staff and management. This was done so in order to gain a general perspective, without any bias, of how the general populous view knowledge management in their institutions. The sampling procedure used in this research was random sampling method. Random sampling is a type of probability sampling where everyone in the entire target population has an equal chance of being selected (McLeod, 2019). According to Horton (2021), random sampling is an unbiased approach to garner the responses from a large group, however, it has its own drawbacks such as time needed to gather the full list of a specific population, the capital needed to retrieve and contact that list, and the bias that could occur when the sample set is not large enough to adequately represent the full population. The advantages are lack of bias and simplicity in its use. At the time of this research, the total target population was 1846 of eligible respondents. The sample size arrived at was 329 . The issued questionnaires were 329, completed questionnaires were 130, while 199 were not completed giving a response rate of $40 \%$.

The sample size was determined using the Yamane formula as follows; $n=N / 1+N\left(e^{2}\right)$ with $5 \%$ error. $n=$ sample size, $N=$ population size, $e$ (margin of error) at $5 \%(0.05)$.

$$
\begin{aligned}
& n=1846 / 1+1846\left(0.05^{2}\right) \\
& n=1846 / 5.615 \\
& n=328.7622 \\
& n=329 . \text { Rounded up to a whole number. }
\end{aligned}
$$

\section{Results and Discussion}

This section displays and discusses the descriptive and inferential statistical results from the study. Data was analysed using descriptive analysis and Pearson Chi-Square analysis was used to determine the relationship between the variables.

\subsection{Basic Statistical Analysis}

\subsubsection{Demographic Information}

Successful participants were 130 from the four selected higher education institu- 
tions (HEIs). The majority of respondents were male at $61 \%$ whereas the female representation was at $31 \%$ as shown in Figure 3. Institutional representation was as follows; $46 \%$ UNZA, 21\% Mulungushi university, 18\% NIPA and 15\% Chalimbana university, as illustrated in Figure 4. In terms or educational background as can be seen in Figure 5, 5\% were PhD degree holders, 46\% hold Master's degree, $34 \%$ had bachelor's degree and $15 \%$ represented those with diplomas and certificates. In terms of occupation, 95 of the respondents were non-academicians whereas 35 were academicians this is shown in Figure 6.

\subsubsection{Knowledge Management Status and Awareness}

This section gives a general overview of the KM status in the studied institutions, as well as the KM awareness among the members of staff. Table 2 shows the respondents' level of KM awareness. This question wanted to find out if the respondents had prior knowledge or awareness of what KM is. From Table 2, the majority of respondents had a good awareness of what KM is. 50 responded good whereas 20 responded very good, 45 respondents have a moderate awareness, whereas 10 have poor awareness of it and 5 very poor sense of awareness. Table 3 gives insights into people's awareness of any KM department in

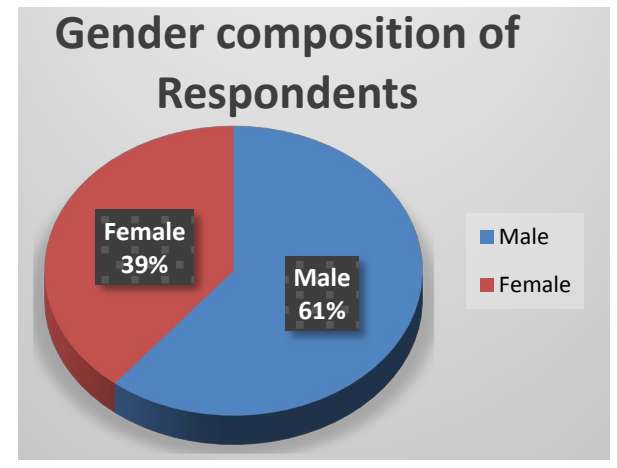

Figure 3. Gender of respondents. Source: study analysis.

\section{Distribution by Institution}

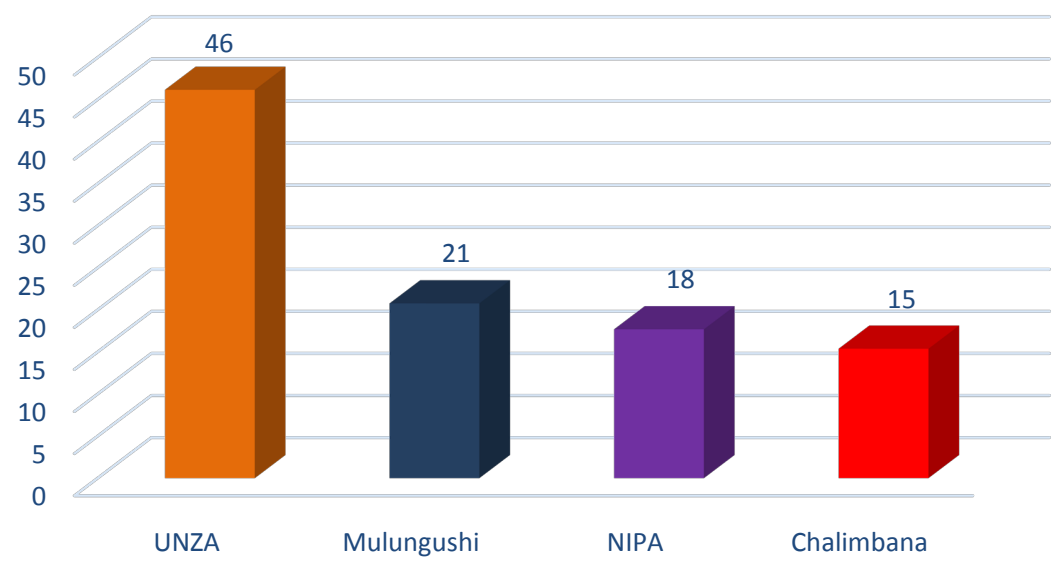

Figure 4. Distribution by institution. Source: study analysis. 


\section{Education level of Respondents}

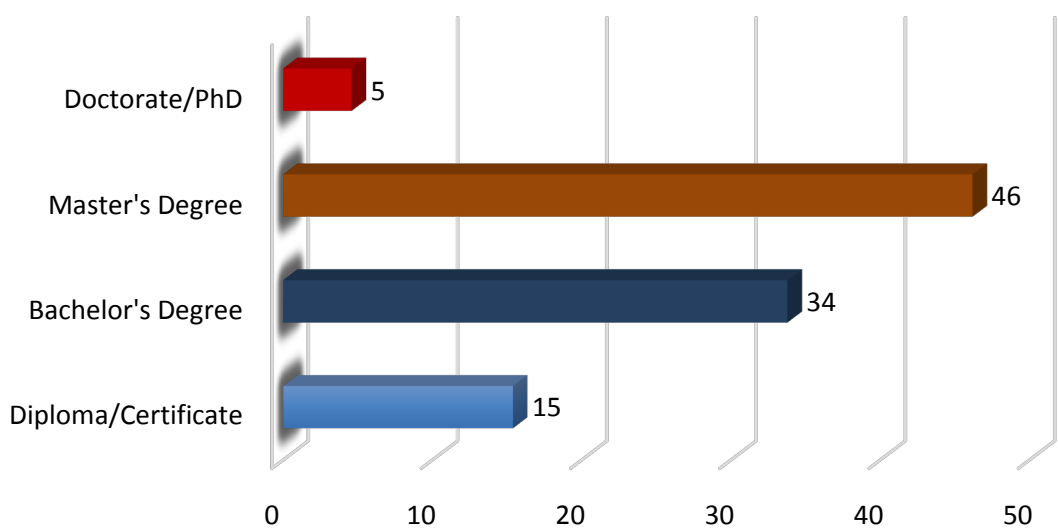

Figure 5. Education level of respondents. Source: study analysis.

\section{REPRESENTATION OF OCCUPATION BY CATEGORY}

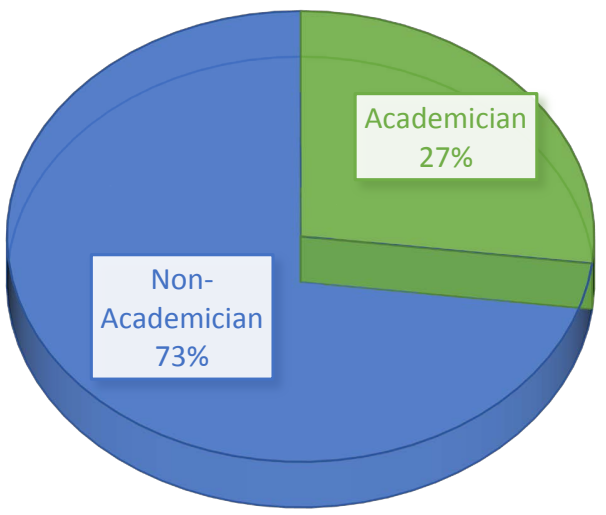

Figure 6. Representation of occupation by category. Source: study analysis.

Table 2. KM awareness.

\begin{tabular}{ccccc}
\hline \multicolumn{6}{l}{ How do you describe your general awareness of KM? } \\
\hline & Frequency & Percent & Valid Percent & Cumulative Percent \\
\hline Very Poor & 5 & 3.8 & 3.8 & 3.8 \\
Poor & 10 & 7.7 & 7.7 & 11.5 \\
Moderate & 45 & 34.6 & 34.6 & 46.2 \\
Good & 50 & 38.5 & 38.5 & 84.6 \\
Very Good & 20 & 15.4 & 15.4 & 100.0 \\
Total & 130 & 100.0 & 100.0 &
\end{tabular}

Source: study analysis.

their institution. The majority, 61 of them indicated no to having a KM department in their institution. 44 indicate don't know and 25 indicated yes. The question in Table 4 wanted to know the level at which $\mathrm{KM}$ is practiced if at all it was 
Table 3. KM department.

\begin{tabular}{ccccc}
\hline \multicolumn{5}{l}{ Does your organization have a KM Department? } \\
\hline & Frequency & Percent & Valid Percent & Cumulative Percent \\
\hline Yes & 25 & 19.2 & 19.2 & 19.2 \\
No & 61 & 46.9 & 46.9 & 66.2 \\
Don't know & 44 & 33.8 & 33.8 & 100.0 \\
Total & 130 & 100.0 & 100.0 & \\
\hline
\end{tabular}

Source: study analysis.

Table 4. Status of KM practices.

\begin{tabular}{ccccc}
\hline What is the current status of KM practices in the Institution? & \\
\hline & Frequency & Percent & Valid Percent & Cumulative Percent \\
\hline Non-existent & 44 & 33.8 & 33.8 & 33.8 \\
Introduction Stage & 40 & 30.8 & 30.8 & 64.6 \\
Intermediate Stage & 30 & 23.1 & 23.1 & 87.7 \\
Growth Stage & 16 & 12.3 & 12.3 & 100.0 \\
Total & 130 & 100.0 & 100.0 & \\
\hline
\end{tabular}

Source: study analysis.

being practiced. 44 said it is non-existent 40 indicated introductory stage, 30 respondents indicated Intermediate Stage whereas 16 respondents indicated that $\mathrm{KM}$ is in its growth stage. Table 5 is displaying responses from respondents after they were asked if they are aware of having a KM policy in their institution. 18 of them indicated yes to having a KM policy, 39 of them said no and 73 indicated don't know. To have a KM strategy, the responses were as follows; 17 said yes, 65 said no and 48 indicated no as shown in Table 6. Respondents were asked if the culture in their institution supported KM, and 56 indicated yes, 59 said no and 25 said no as illustrated in Table 7.

\subsection{Hypothesis Analysis}

Four hypotheses were tested using Pearson chi-square test of independence. Table 8 shows the results of whether there is a relationship between organizational strategy and knowledge management practice. Pearson Chi-Square test statistic 163.502 ( $P$-value 0.001$)$. According to the chi-square results, the $p$-value $(0.001)$ is less than the significance level of 0.05 , therefore, the test is significant and we reject the null hypothesis and conclude there is evidence to suggest, that there is a relationship between organizational strategy and Knowledge management practice.

Table 9 shows chi-square test results of whether there is a relationship between organizational culture and knowledge management practice. Pearson Chi-Square test statistic 176.637 ( $P$-value 0.000$)$. According to the chi-square results, the 
Table 5. KM policy.

\begin{tabular}{ccccc}
\hline \multicolumn{5}{l}{ Is there written KM policy in the institution } \\
\hline & Frequency & Percent & Valid Percent & Cumulative Percent \\
\hline Yes & 18 & 13.8 & 13.8 & 13.8 \\
No & 39 & 30.0 & 30.0 & 43.8 \\
Don't know & 73 & 56.2 & 56.2 & 100.0 \\
Total & 130 & 100.0 & 100.0 & \\
\hline
\end{tabular}

Source: study analysis.

Table 6. KM strategy.

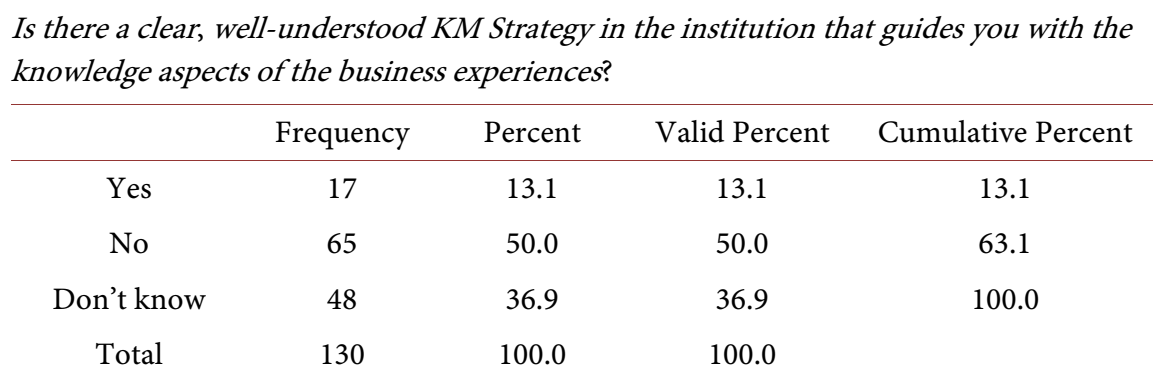

Source: study analysis.

Table 7. KM culture.

\begin{tabular}{|c|c|c|c|c|}
\hline \multicolumn{5}{|c|}{ Does the culture in your organization support KM? } \\
\hline & Frequency & Percent & Valid Percent & Cumulative Percent \\
\hline Yes & 46 & 35.4 & 35.4 & 35.4 \\
\hline No & 59 & 45.4 & 45.4 & 80.8 \\
\hline Don't know & 25 & 19.2 & 19.2 & 100.0 \\
\hline Total & 130 & 100.0 & 100.0 & \\
\hline
\end{tabular}

Source: study analysis.

Table 8. Strategy/knowledge management practice.

\begin{tabular}{cccc}
\hline & \multicolumn{3}{c}{ Chi-Square Tests } \\
\cline { 2 - 4 } & Value & $\mathrm{df}$ & Asymp. Sig. (2-sided) \\
\hline Pearson Chi-Square & $163.502 \mathrm{a}$ & 112 & 0.001 \\
Likelihood Ratio & 173.450 & 112 & 0.000 \\
Linear-by-Linear Association & 3.198 & 1 & 0.074 \\
N of Valid Cases & 130 & & \\
\hline
\end{tabular}

Pearson Chi-Square statistic, $\chi^{2}=163.502$, and $p<0.05$. The null hypothesis is rejected, since $p<0.05$. Source: study analysis.

$p$-value (0.000) is less than the significance level of 0.05 , therefore, the test is significant and we reject the null hypothesis and conclude there is evidence to sug- 
gest, that there is a relationship between organizational culture and Knowledge management practice.

A Chi-square Pearson was done to determine if there was a relationship between organisational structure and Knowledge management practice. It was found that organisational structure and Knowledge management practice have a relationship with a $p$-value (Sig. 2 -sided) 0.002 as shown in Table 10.

Table 11 shows a chi-square done to determine the relationship between policy and Knowledge management practice. Pearson Chi-Square test statistic 154.403 ( $P$-value 0.005$).$ According to the chi-square results, the $p$-value $(0.005)$ is less that the significance level of 0.05 , therefore, the test is significant and we reject the null hypothesis and conclude there is evidence to suggest, there is a relationship between organisational and knowledge management practice. Table 12 shows a summary of the hypotheses of tests done based on the conceptual framework.

Table 9. Culture/knowledge management practice.

\begin{tabular}{cccc}
\hline & \multicolumn{3}{c}{ Chi-Square Tests } \\
\cline { 2 - 4 } & Value & df & Asymp. Sig. (2-sided) \\
\hline Pearson Chi-Square & $176.637 \mathrm{a}$ & 112 & 0.000 \\
Likelihood Ratio & 194.533 & 112 & 0.000 \\
Linear-by-Linear Association & 15.470 & 1 & 0.000 \\
N of Valid Cases & 130 & & \\
\hline
\end{tabular}

Pearson Chi-Square statistic, $\chi^{2}=176.637$, and $p<0.05$. The null hypothesis is rejected, since $p<0.05$. Source: study analysis.

Table 10. Structure/knowledge management practice.

\begin{tabular}{cccc}
\hline & \multicolumn{3}{c}{ Chi-Square Tests } \\
\cline { 2 - 4 } & Value & $\mathrm{df}$ & Asymp. Sig. (2-sided) \\
\hline Pearson Chi-Square & $160.109 \mathrm{a}$ & 112 & 0.002 \\
Likelihood Ratio & 172.891 & 112 & 0.000 \\
Linear-by-Linear Association & 1.068 & 1 & 0.301 \\
N of Valid Cases & 130 & & \\
\hline
\end{tabular}

Pearson Chi-Square statistic, $\chi^{2}=160.109$, and $p<0.05$. The null hypothesis is rejected, since $p<0.05$. Source: study analysis.

Table 11. Policy/knowledge management practice.

\begin{tabular}{cccc}
\hline & \multicolumn{3}{c}{ Chi-Square Tests } \\
\cline { 2 - 4 } & Value & $\mathrm{df}$ & Asymp. Sig. (2-sided) \\
\hline Pearson Chi-Square & $154.403 \mathrm{a}$ & 112 & 0.005 \\
Likelihood Ratio & 163.001 & 112 & 0.001 \\
Linear-by-Linear Association & 13.346 & 1 & 0.000 \\
N of Valid Cases & 130 & & \\
\hline
\end{tabular}

Pearson Chi-Square statistic, $\chi^{2}=154.403$, and $p<0.05$. The null hypothesis is rejected, since $p<0.05$. Source: study analysis. 
Table 12. Summary of hypotheses results.

\begin{tabular}{lcc}
\hline \multicolumn{1}{c}{ Hypothesis } & Sig. & Decision at $\alpha=0.05$ \\
\hline $\begin{array}{l}\text { H1: There is a relationship between organizational } \\
\text { strategy and knowledge management practice }\end{array}$ & 0.001 & Accepted \\
$\begin{array}{l}\text { H2: There is a relationship between organizational } \\
\text { culture and Knowledge management practice }\end{array}$ & 0.000 & Accepted \\
$\begin{array}{l}\text { H3: There is a relationship between organizational } \\
\text { structure and knowledge management practice }\end{array}$ & 0.002 & Accepted \\
$\begin{array}{l}\text { H4: There is a relationship between organisational KM } \\
\text { policy and knowledge management practice }\end{array}$ & 0.005 & Accepted
\end{tabular}

Source: study result analysis.

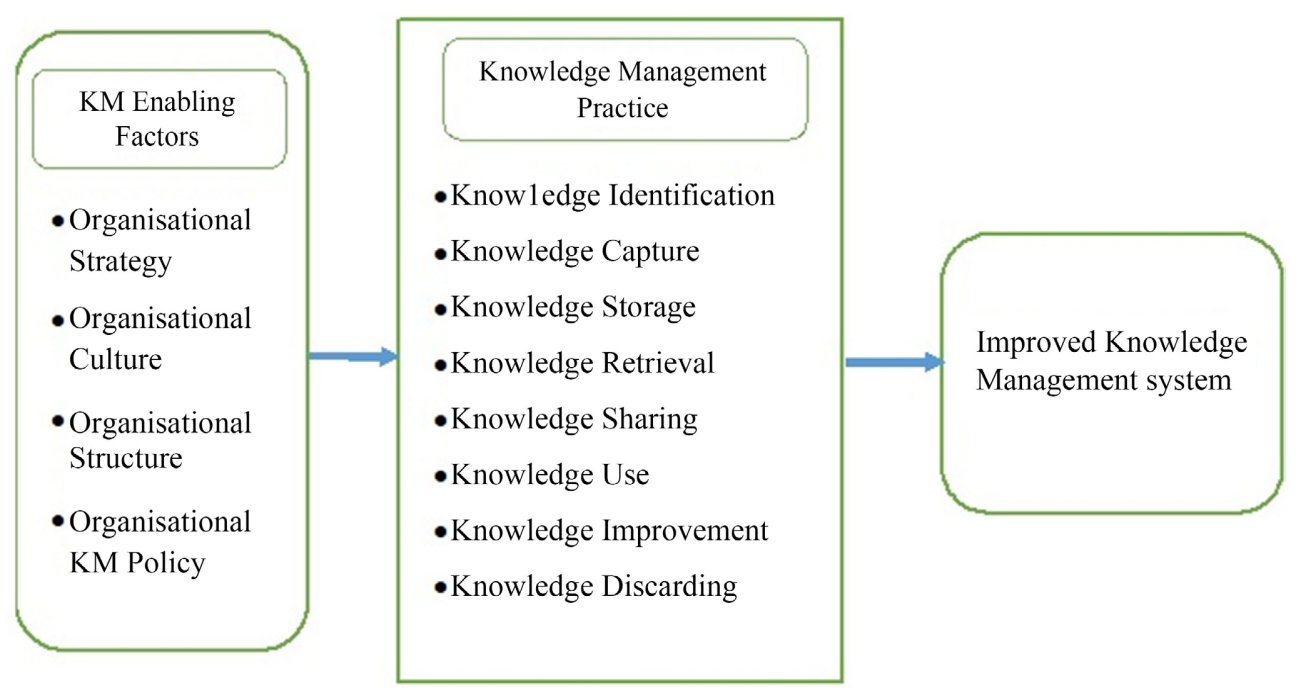

Figure 7. Proposed KM model. Source: researcher's own construction.

\section{Conclusion and Recommendation}

The purpose of this study was to develop a model that would assist with the adoption of knowledge management practices in Higher Education Institutions in Zambia. Following Heisig's (2009) model of CSFs with the exception of the technological factor, the results showed that the proposed model, as shown in Figure 7, does provide important factors to consider as institutions plan for KM implementation. The study scrutinized knowledge management practices in four higher education institutions in Zambia. These institutions were deliberately sampled, as they were able to represent the highest learning institution in the country, UNZA, a more recently introduced university (Mulungushi University), a long standing reputable college (NIPA) and another former college turned into a University (Chalimbana University).

From the findings of the study, the following conclusions were made: Given the positive association between organisational strategy and knowledge management practice, and rejecting the null hypothesis, it was concluded that orga- 
nisational culture has a significant influence on knowledge management practice. Given a positive relationship between organisational culture and rejecting the null hypothesis, it was concluded that there is a significant relationship between organisational culture and knowledge management practice. The study findings showed that the association between organisational structure and knowledge management practice was positive and the null hypothesis was rejected indicating that organisational structure is important for improved knowledge management practices. Finally, the study revealed that there was a positive relationship between organisational knowledge management policy and knowledge management practice, as well as rejecting the null hypothesis, meaning that organisational knowledge management policy is necessary for improved knowledge management practice.

The researcher recommends the following; with the right KM strategies in place, only then can the knowledge management processes be put into proper practice. Knowledge Management should be part of the organisational strategic plan; management and decision makers in higher education institutions should actively promote the culture of knowledge creation and use. Management should encourage a positive orientation to knowledge among the members of staff, which promotes intellectual curiosity, freedom to explore new knowledge and a willingness to share knowledge without fearing loss of power or positions held in the institution. Culture is among the critical success factors for KM; management and decision makers in the higher education institutions must attach great importance in the way the institutions are structured in order to promote proper knowledge management. This can be achieved by having a well-established and structured knowledge management department with clearly defined roles and duties occupied by knowledgeable and well informed staff; management and decision makers of higher education institutions to develop a detailed knowledge management policy that can serve as a foundation for the other strategic knowledge management practices. The knowledge management policy should precede the other strategic knowledge management practices. The KM policy will guide the knowledge management strategies, it will assist to promote knowledge management culture in the institutions and among the members of staff, the policy will serve as a guideline when formulating a knowledge-management presence by emphasizing having a KM department and communities of practice within the institution.

\section{Future Research}

The current study was restricted to only four higher education institutions and only considered four knowledge management critical factors for knowledge management practice improvement. Future studies should include higher learning institutions, including both public and private, in order to have a broader representation of HEIs. This study only included four public HEIs, therefore did not represent the private HEIs. Furthermore, future studies should explore more 
knowledge management critical factors in addition to the four factors covered in this study.

\section{Limitations}

The major limitation for this study was that the response rate was quite low at only $40 \%$ of the target population. This was mainly attributed to the fact that at the time of data collection, most institutions were on lock down due to the COVID19 pandemic. The other limitation is that the target population was not categorized into different job affiliations, such as, academicians, administrative staff and management. The population was treated as one homogeneous population. The idea was to get a general opinion at the institutions, the assumption was that such a huge practice such as knowledge management would be known by the masses if it did really exist and was being taken seriously as a practice.

Another limitation of this study is that only 4 public HEIs were selected and did not include a privately owned institution, which would have provided a broader view on KM statuses in different institutions apart from the state owned one. The other limitation is that the technology factor from the theoretical framework was not included in the conceptual framework for this research. The researcher wanted to concentrate more on the other factors; Human factor, organization factor and management process. However, the Human factor only included culture, the organization factor only included structure, whereas the management process only included strategy, however, the researcher included policy. Future research can include more critical success factors for KM implementation and can also include both public and privately owned HEIs in the study in order to have a broader picture of the prevailing status.

\section{Acknowledgements}

The authors would like to acknowledge all those who participated in the study.

\section{Conflicts of Interest}

The authors declare no conflicts of interest regarding the publication of this paper.

\section{References}

Ahmady, G. A., Mehrpour, M., \& Nikooravesh, A. (2016). Organizational Structure. Procedia-Social and Behavioral Sciences, 230, 455-462. https://doi.org/10.1016/j.sbspro.2016.09.057

Al-Hayaly, M., \& Alnajjar, F. (2016). Knowledge Management Processes and Their Impact on Organizational Performance, the Adoption Balanced Scorecard: The Moderating Role of Quality Assurance Standards-An Applied Study on Private Jordanian Universities. International Journal of Business and Management, 11, 70-86. https://doi.org/10.5539/ijbm.v11n6p70

Allameh, S. M., Zare, S. M., \& Davoodi, S. M. R. (2011). Examining the Impact of KM Enablers on Knowledge Management Processes. Procedia Computer Science, 3, 1211-1223. 
https://doi.org/10.1016/j.procs.2010.12.196

Balague, N., Düren, P., \& Saarti, J. (2016). Comparing the Knowledge Management Practices in Selected European Higher Education Libraries. Library Management, 37, 182-194. https://doi.org/10.1108/LM-12-2015-0068

Cabrita, M., Machado, V., \& Grilo, A. (2010). Leveraging Knowledge Management with the Balanced Scorecard. In International Conference on Industrial Engineering and Engineering Management (pp. 1066-1071). IEEE . https://ieeexplore.ieee.org/document/5674245 https://doi.org/10.1109/IEEM.2010.5674245

Chitumbo, E., \& Kanyengo, C. (2017). Knowledge Management Culture among Library Cataloguers: The University of Zambia Library Experience. Library Philosophy and Practice (e-Journal). http://digitalcommons.unl.edu/libphilprac/1561

Dhamdhere, S. (2015). Importance of Knowledge Management in Higher Education Institutes. Turkish Online Journal of Distance Education, 16, 162-183.

https://www.researchgate.net/publication/272295725 Importance of Knowledge Man agement in Higher Education Institutes https://doi.org/10.17718/tojde.34392

Evans, M. M., Dalkir, K., \& Bidian, C. (2014). A Holistic View of the Knowledge Life Cycle: The Knowledge Management Cycle (KMC) Model. Electronic Journal of Knowledge Management, 12, 85-97.

https://academic-publishing.org/index.php/ejkm/article/view/1015

Fteimi, N. (2015). Analyzing the Literature on Knowledge Management Frameworks: Towards a Normative Knowledge Management Classification Schema. In Proceedings ECIS (Paper 51). https://aisel.aisnet.org/ecis2015 cr/51

Ho, O. (2018). Knowledge Management. Journal of Business \& Financial Affairs, 7, 335. https://doi.org/10.4172/2167-0234.1000335

Hoq, K., \& Akter, R. (2012). Knowledge Management in Universities: Role of Knowledge Workers. Bangladesh Journal of Library and Information Science, 2, 92-102. https://doi.org/10.3329/bjlis.v2i1.12925

Horton, M. (2021). Simple Random Sample: Advantages and Disadvantages. https://www.investopedia.com/ask/answers/042815/what-are-disadvantages-using-sim ple-random-sample-approximate-larger-population.asp

Johnson, S. (2019). What Is the Meaning of Organizational Strategy? https://smallbusiness.chron.com/meaning-organizational-strategy-59427.html

Kabilwa, S., \& Maasdorp, C. (2017). Determining the State of Knowledge Management in Higher Education Institutions in Zambia: An Exploratory Study of Public Universities. The International Journal of Multi-Disciplinary Research, 1-10. http://www.multiresearch.net/cms/publications/CFP2432017.pdf

Kumaravel, V., \& Vikkraman, P. (2018). Assessment of Knowledge Management Practices in Higher Educational Institutions in India: A Structural Equation Modeling Approach. International Journal of Educational Science, 20, 120-136.

https://doi.org/10.31901/24566322.2018/20.1-3.15 http://krepublishers.com/02-Journals/IJES/IJES-20-0-000-18-Web/IJES-20-1-3-000-18Abst-PDF/IJES-20-1-3-120-18-1055-Kumaravel-V/IJES-20-1-3-120-18-1055-Kumarav el-V-Tx[15].pmd.pdf

Laerd Statistics (2020). https://statistics.laerd.com/spss-tutorials/cronbachs-alpha-using-spss-statistics.php

Lee, H., \& Roth, G. L. (2009). A Conceptual Framework for Examining Knowledge Man- 
agement in Higher Education Contexts. New Horizons in Adult Education and Human Resource Development, 23, 22-37. https://doi.org/10.1002/nha3.10357

Lyu, H., Zhou, Z., \& Zhang, Z. (2016). Measuring Knowledge Management Performance in Organizations: An Integrative Framework of Balanced Scorecard and Fuzzy Evaluation. Information, 7, 29. https://doi.org/10.3390/info7020029

McLeod, S. A. (2019). Sampling Methods. Simply Psychology. https://www.simplypsychology.org/sampling.html

Moghaddam, A., Mosakhani, M., \& Aalabeiki, M. (2013). A Study on Relationships between Critical Success Factors of Knowledge Management and Competitive Advantage. Management Science Letters, 3, 2915-2922. https://doi.org/10.5267/j.msl.2013.11.006

Mohajan, H. K. (2016). A Comprehensive Analysis of Knowledge Management Cycles. Journal of Environmental Treatment Techniques, 4, 121-129. https://www.researchgate.net/publication/313678837 A Comprehensive Analysis of Knowledge Management Cycles

Mvula, M. (2018). Knowledge Management Practices in University Administration: The Case of the University of Zambia. Master's Thesis, Stellenbosch University. http://hdl.handle.net/10019.1/103711

Ngoc-Tan, N., \& Gregar, A. (2018). Impacts of Knowledge Management on Innovation in Higher Education Institutions: An Empirical Evidence from Vietnam. Economics and Sociology, 11, 301-320. https://doi.org/10.14254/2071-789X.2018/11-3/18

Omotayo, F. O. (2015). Knowledge Management as an Important Tool in Organizational Management: A Review of Literature. Library Philosophy and Practice (e-Journal). http://digitalcommons.unl.edu/libphilprac/1238

Paul, P. (n.d.). 4 Knowledge Management Models That Can Supercharge Your Organization. https://helpiewp.com/knowledge-management-models

Siregar, Z. M. E., Suryana, A. E., \& Senen, S. H. (2019). Does Knowledge Management Enhance Innovation: A Literature Review. International Journal of Scientific \& Technology Research, 8, 1991-1994.

https://www.researchgate.net/profile/Zulkifli Siregar/publication/336995121 Does Kn ow-

ledge Management Enhance_Innovation A Literature Review/links/5dbe957f458515 $\underline{1435 \mathrm{e} 2705 \mathrm{~b} / \text { Does-Knowledge-Management-Enhance-Innovation-A-Literature-Review }}$ .pdf

Snook, A. (2021). What Are Policies and Procedures? https://www.i-sight.com/resources/policies-and-procedures-in-the-workplace-the-ulti mate-guide

Statistics Solutions (2021). Cronbach's Alpha. https://www.statisticssolutions.com/cronbachs-alpha

Torabi, F., \& El-Den, J. (2017). The Impact of Knowledge Management on Organizational Productivity: A Case Study on Koosar Bank of Iran. Procedia Computer Science, 124, 300-310. https://doi.org/10.1016/j.procs.2017.12.159

Twaambo, E. (2018). Research Practices of Academics in an African University Setting: The Case of the University of Zambia. Master's Thesis, Stellenbosch University. http://hdl.handle.net/10019.1/103760

Wamundila, S., \& Ngulube, P. (2011). Enhancing Knowledge Retention in Higher Education: A Case of the University of Zambia. SA Journal of Information Management, 13, Article 439. https://hdl.handle.net/10520/EJC46347

https://doi.org/10.4102/sajim.v13i1.439 